\title{
Rac1-Mediated Endocytosis during Ephrin-A2- and Semaphorin 3A-Induced Growth Cone Collapse
}

\author{
William M. Jurney, ${ }^{*}$ Gianluca Gallo, ${ }^{*}$ Paul C. Letourneau, and Steven C. McLoon \\ Department of Neuroscience, University of Minnesota, Minneapolis, Minnesota 55455
}

Negative guidance molecules are important for guiding the growth of axons and ultimately for determining the wiring pattern in the developing nervous system. In tissue culture, growth cones at the tips of growing axons collapse in response to negative guidance molecules, such as ephrin-A2 and semaphorin 3A. The small GTPase Rac1 is involved in growth cone collapse, but the nature of its role is not clear. Rac1 activity assays showed that Rac1 is transiently inactivated after treatment with ephrin-A2. Ephrin-induced growth cone collapse, however, correlated with resumption of Rac1 activity. We demonstrate that Rac1 is required for endocytosis of the growth cone plasma membrane and reorganization of F-actin but not for the depolymerization of F-actin during growth cone collapse

Growth cones at the leading end of growing axons navigate a complex extracellular environment to reach their targets. En route, they encounter both "positive" and "negative" guidance molecules. Positive cues promote axon extension, whereas negative cues cause growth cones to turn away, slow, or stop growing. In tissue culture, growth cones typically collapse in response to negative guidance molecules. Families of molecules that cause growth cone collapse have been identified, including semaphorins and ephrins. Semaphorin 3A collapses growth cones of sensory and sympathetic axons (Luo et al., 1993), and knock-out of semaphorin 3A results in guidance defects in peripheral nerves (Behar et al., 1996; Taniguchi et al., 1997). Ephrin-A2 is expressed in a gradient in the developing optic tectum, a major brain target of retinal axons (Cheng et al., 1995; Drescher et al., 1995). In vitro, ephrin-A2 collapses the growth cones of axons from the temporal side of the retina (Monschau et al., 1997). As demonstrated by studies of transgenic mice, ephrin-A2 contributes to specifying the site at which retinal axons terminate in the tectum (Frisen et al., 1998; Feldheim et al., 2000). The signal transduction mechanisms mediating the response of growth cones to these molecules are incompletely characterized. A general feature of the response of growth cones to negative guidance cues is the depolymerization of actin filaments (F-actin; Fan and Raper, 1995; Kuhn et al., 1999; Ernst et al., 2000; Fournier et al., 2000). Pharmacological agents that cause F-actin depolymeriza-

Received Jan. 28, 2002; revised April 16, 2002; accepted April 19, 2002.

This work was supported by National Institutes of Health Grants EY07133, EY111926, and HD19950 and by National Science Foundation Grant IBN80932. We are grateful to C. Ercole (University of Minnesota) for technical assistance, T. Kuhn for the gift of adenovirus, and $\mathrm{S}$. Ng for the gift of semaphorin 3A-producing cells.

*W.M.J. and G.G. contributed equally to this work.

Correspondence should be addressed to Steven C. McLoon, Department of Neuroscience, University of Minnesota, 6-145 Jackson Hall, 321 Church Street Southeast, Minneapolis, MN 55455. E-mail: mcloons@umn.edu.

Copyright (C) 2002 Society for Neuroscience $0270-6474 / 02 / 220001-10 \$ 15.00 / 0$ in response to ephrin-A2 and semaphorin 3A. Rac1, however, does not regulate constitutive endocytosis in growth cones. These findings show that in response to negative guidance molecules, the function of Rac1 changes from promoting actin polymerization associated with axon growth to driving endocytosis of the plasma membrane, resulting in growth cone collapse. Furthermore, Rac1 antisense injected into the embryonic chick eye in vivo caused the retinotectal projection to develop without normal topography in a manner consistent with Rac1 having an obligatory role in mediating ephrin signaling.

Key words: development; axon guidance; growth cone; ephrin; semaphorin; endocytosis; actin; retina

tion cause growth cone collapse (Letourneau et al., 1987). For this reason, studies of the mechanisms of growth cone collapse have focused on molecules that regulate actin dynamics and organization.

Rac1 is a small GTPase of the Rho family that has been implicated in regulation of actin polymerization and organization. A major role of Rac1 is to promote actin polymerization and to drive lamellipodial extension of growth cones (Hall, 1998; Kuhn et al., 1999). Rac1 is required for axonogenesis (Ruchhoeft et al., 1999) and has a role in axon pathfinding in vivo (Steven et al., 1998; Allen et al., 2000; Newsome et al., 2000). Expression of a dominant negative Rac1 or inhibition of Rac1 signaling blocks growth cone collapse in response to semaphorin 3A, demonstrating that Rac1 activity can be required for growth cone collapse (Jin and Strittmatter, 1997; Kuhn et al., 1999; Vastrik et al., 1999). This observation is paradoxical, considering that Rac1 promotes actin polymerization in growth cones, and actin depolymerization is associated with growth cone collapse. Thus, the role of Rac1 during growth cone collapse is not clear.

Here we report that Rac1 activity is required for growth cones to respond to ephrin-A2. Although Rac1 activity decreased immediately after ephrin-A2 exposure, a decrease in F-actin levels and onset of growth cone collapse coincided with the subsequent return of Rac1 activity to control levels. Interfering with Rac1 signaling blocked the ability of ephrin-A2 to collapse retinal or sensory growth cones, but it did not affect $\mathrm{F}$-actin depolymerization. Both ephrin-A2 and semaphorin 3A increased endocytosis in growth cones, and inhibition of Rac1 signaling blocked ligandinduced but not constitutive endocytosis. Finally, reduction of Rac1 expression in the developing retina in vivo resulted in an abnormal retinotectal projection.

\section{MATERIALS AND METHODS}

Reagents. Ephrin-A2/Fc was from R \& D Systems (Minneapolis, MN). A Rac1 activation assay kit, including a polyclonal antibody to Rac1, was 
from Upstate Biotechnology (Lake Placid, NY). Rac1 inhibitory peptide was from American Peptide Co., Inc. (Sunnyvale, CA). Oligonucleotides were from Oligos Etc. (Bethel, ME). Protein assays were performed using the BCA protein assay kit from Pierce (Rockford, IL). V12Rac1and LacZ-expressing adenoviruses were generously provided by Dr. Thomas B. Kuhn (University of Alaska, Fairbanks, AK). Semaphorin 3A-expressing 293 cells were generously provided by Sheldon $\mathrm{Ng}$ (Exelixis Inc., South San Francisco, CA). Latrunculin A was from Molecular Probes (Eugene, OR). All media and other reagents were from Sigma (St. Louis, MO) unless otherwise noted.

Cell culture. Fertilized White Leghorn chicken eggs were obtained from the University of Minnesota Poultry Center. All neurons were grown on plastic or glass incubated overnight with $25 \mu \mathrm{g} / \mathrm{ml}$ laminin. Neurons were cultured in F12 defined medium containing additives as described previously (Ernst et al., 2000). Retina from embryos on the seventh day of development [embryonic day 7 (E7)] or E9 dorsal root ganglia (DRG) were dissected. Retinas were cut into thirds, and explants $(\sim 500 \times 500 \mu \mathrm{m})$ were cut from the temporal third only. After appropriate treatment, the number of collapsed growth cones was counted and expressed as a percentage of the total number of growth cones. A collapsed growth cone was defined by the absence of lamellipodia and having less than three filopodia. For determination of DRG neuron responsiveness to ephrin-A2, DRG explants were cultured overnight in F12 defined medium containing $20 \mathrm{ng} / \mathrm{ml}$ neurotrophin [brain-derived neurotrophic factor (BDNF), neurotrophin-3, or nerve growth factor (NGF)]. For viral infection studies, dissociated DRG neurons were plated in $1 \mathrm{ml}$ of $\mathrm{F} 12$ defined medium containing $10 \mathrm{ng} / \mathrm{ml}$ BDNF. Neurons were allowed to attach for $4 \mathrm{hr}$ at $40^{\circ} \mathrm{C}$ and then were infected with virus at a multiplicity of infection of 300 .

Rac1 activation assay. Tissue was prepared in one of two ways. Temporal retinal thirds were dissected, pooled, incubated in $0.2 \%$ trypsin for $10 \mathrm{~min}$ at $37^{\circ} \mathrm{C}$, and dissociated by mechanical trituration. The dissociated cells were divided into equal portions, equivalent to three temporal retinal thirds per treatment. The retinal cells were either cultured overnight or used immediately. The dissociated retinal cells were exposed to $1.0 \mu \mathrm{g} / \mathrm{ml}$ ephrin-A2 for various times, and detection of GTP-bound Rac1 was performed as outlined in the Rac1 activation assay kit, with modifications suggested by Dr. Gary Bokoch (Scripps Research Institute, La Jolla, CA).

Reduction of Rac1 expression. The Rac1 antisense oligonucleotide was used previously in rat (Dorseuil et al., 1992) and with a single nucleotide change (indicated below in bold), was complementary to chicken Rac1 mRNA. The oligonucleotide spans the ATG initiation codon and was constructed using phosphorothioate chemistry (5'ACTTgATCgCCTgCAT-3'). The missense (control) oligonucleotide had five base substitutions (underlined below) from the antisense sequence $\left(5^{\prime}-\underline{T C T} \underline{A g} \underline{A} \underline{A} \operatorname{ggCTCCA} \underline{A}-3^{\prime}\right)$. The efficacy of the antisense treatment was tested by culturing dissociated retinal cells for 24 $\mathrm{hr}$ in the presence of antisense or missense oligonucleotide, lysing the cells, and performing an immunoblot analysis. Retinal explant cultures were cultured overnight in the presence of 5-10 $\mu \mathrm{M}$ missense or antisense oligonucleotide, treated for $15 \mathrm{~min}$ with $0.5 \mu \mathrm{g} / \mathrm{ml}$ ephrin-A2, fixed in $0.25 \%$ glutaraldehyde, and analyzed for growth cone collapse. Oligonucleotide treatments in vivo were performed on chick embryos removed from the shell on E2 and cultured as described previously (Wu et al., 2001). A $1 \mu \mathrm{l}$ injection of antisense or missense oligonucleotide was made into the vitreous chamber of the left eye on E6 and again on E8. The final concentration inside the eye was $\sim 5 \mu \mathrm{M}$. On E10, a $0.25 \mu \mathrm{l}$ injection of $10 \%$ DiI (Molecular Probes) in $N, N$-dimethyl-formamide was made into the posterior region of the right optic tectum. On E11, embryos were perfused in $4 \%$ paraformaldehyde, and the retinas were dissected from the treated eyes. The retinas were flat-mounted on a microscope slide, and the position of retrogradely labeled ganglion cells was recorded using a fluorescent microscope equipped with stage position encoders. The brain was dissected to confirm the site of the microsphere injection in the middle of the posterior third of the optic tectum.

Histochemistry. F-actin was stained and quantified in growth cones as described previously (Ernst et al., 2000). Briefly, cultures were fixed with $0.25 \%$ glutaraldehyde for $15 \mathrm{~min}$, then treated with $1 \mathrm{mg} / \mathrm{ml}$ sodium borohydrate for $15 \mathrm{~min}$, followed by blocking with $1.0 \%$ fish gelatin, and then stained for $1 \mathrm{hr}$ with rhodamine-labeled phalloidin (Molecular Probes). Microscopic images of F-actin were acquired and analyzed using Metamorph software (Universal Imaging Corp., West Chester, PA). Retinal axon growth into the brain was visualized by immunohis- tochemistry using the RA4 monoclonal antibody (McLoon and Barnes, 1989).

Analysis of endocytosis To visualize endocytotic activity in growth cones, retinal or DRG explants were exposed to a $2.5 \mathrm{mg} / \mathrm{ml}$ concentration of $M_{\mathrm{r}}$ 10,000 lysine-fixable rhodamine-labeled dextran (Molecular Probes). Twenty-four hours after the cultures were established, half of the culture medium was replaced with an equal amount of dextrancontaining medium with or without $1 \mu \mathrm{g} / \mathrm{ml}$ ephrin-A2- or semaphorin 3A-conditioned medium. After a 3-30 min incubation, cultures were washed three times with PBS and then fixed with $4 \%$ paraformaldehyde in PBS with $20 \%$ sucrose added to minimize osmotic shock during fixation. Cultures were counterstained for $1 \mathrm{~min}$ with $5 \mu \mathrm{g} / \mathrm{ml} \mathrm{DiOC} \mathrm{Di}_{6}(3)$ (Molecular Probes) to reveal the morphology of growth cones and axons. DRG cultures were raised in $20 \mathrm{ng} / \mathrm{ml}$ BDNF for ephrin-A2 experiments and in $20 \mathrm{ng} / \mathrm{ml} \mathrm{NGF}$ for semaphorin 3A experiments. Digital images of growth cones were captured with a Photometrics camera on a fluorescence microscope and were deconvolved using Microtome (VayTek) as a subroutine within the Image-Pro Plus program (Media Cybernetics). The endocytotic vesicles in the distal $20 \mu \mathrm{m}$ of axons were counted in the deconvolved optical sections.

Immunoblotting. For each gel, equal amounts of protein were loaded in each lane. Proteins were separated by SDS-PAGE and transferred to nitrocellulose. The blots were blocked with $3 \%$ milk, probed with 1 $\mu \mathrm{g} / \mathrm{ml} \mathrm{Rac1}$ antibody followed by alkaline phosphatase-conjugated secondary antibody (Sigma), and then incubated with nitroblue tetrazolium/ 5-bromo-4-chloro-3-indolyl phosphate substrate (Promega, Madison, WI). The blots were digitized and the bands were quantified using Eastman Kodak (Rochester, NY) gel analysis software.

Protein loading into growth cones. To load proteins into growth cones, we used the Chariot reagent (Active Motif Inc., Carlsbad, CA), a peptide-based method that allows the internalization of exogenously applied proteins into cells. The manufacturer's suggested protocol for a $1 \mathrm{ml}$ culture was followed. Briefly, Chariot was complexed to $1 \mu \mathrm{g}$ of N17Rac1 (Cytoskeleton Inc., Denver, CO) or bovine serum albumin (fraction V; ICN Biochemicals Inc., Aurora, OH) for $30 \mathrm{~min}$ at room temperature. The complex was then added to cultures for $3 \mathrm{hr}$ before using the cultures in experiments.

\section{RESULTS}

The initial aim was to determine whether there is a correlation between the level of activated Rac1 and ephrin-induced collapse of retinal growth cones. Growth cones of axons extending from explants of the temporal side of the retina were monitored by video microscopy before and after ephrin-A2 was added to the culture medium (Fig. 1 $A, C$ ). The first significant increase in the number of collapsed growth cones was seen 6 min after addition of ephrin. The peak number of collapsed growth cones was seen at $12 \mathrm{~min}$ after ephrin addition. The response of growth cones was compared with the level of activated Rac1. Activated, GTPbound Rac1 was precipitated from lysed retinal cells using the p21-binding domain of p21-activated kinase in a glutathione $S$-transferase fusion protein and was visualized by SDS-PAGE (Bernard et al., 1999). Ephrin treatment resulted in a transient reduction in the level of activated Rac1 (Fig. 1B,C). Three minutes after ephrin-A2 treatment, Rac1 activity was reduced $60 \%$ compared with untreated controls. By 6 min after treatment, the level of activated Rac1 started to increase, and by $12 \mathrm{~min}$, it was indistinguishable from the baseline level. Thus, the level of activated Rac1 initially falls in retinal cells in response to ephrin, and the collapse of retinal growth cones correlates temporally with the subsequent reactivation of Rac1.

We next asked whether experimentally induced inactivation of Rac1 would lead to growth cone collapse. A 32-amino acid peptide that consists of the internalization sequence from Antennepedia homeodomain protein combined with amino acids 17-32 of Rac1 has been shown to competitively inhibit the binding of Rac1 to downstream effectors (Vastrik et al., 1999). Retinal cultures were treated with the Rac1 inhibitory peptide for $1 \mathrm{hr}$, and the growth cones were monitored by video microscopy. Con- 

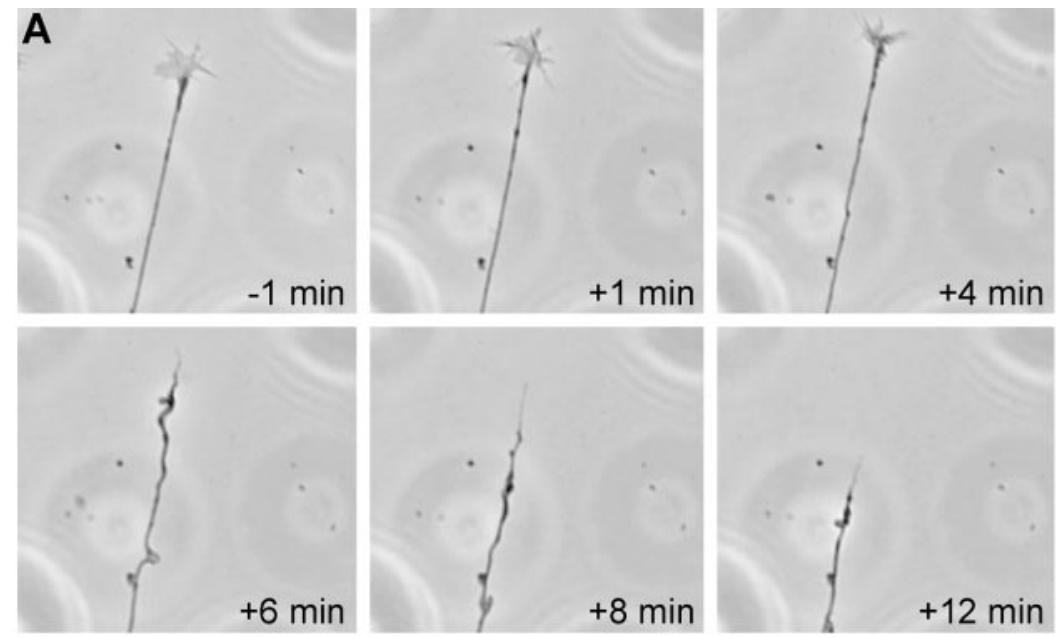

B

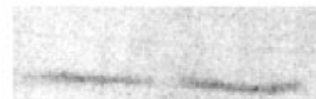

NT

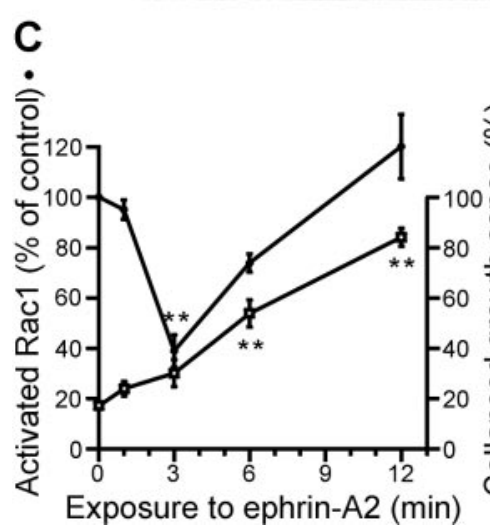

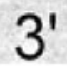

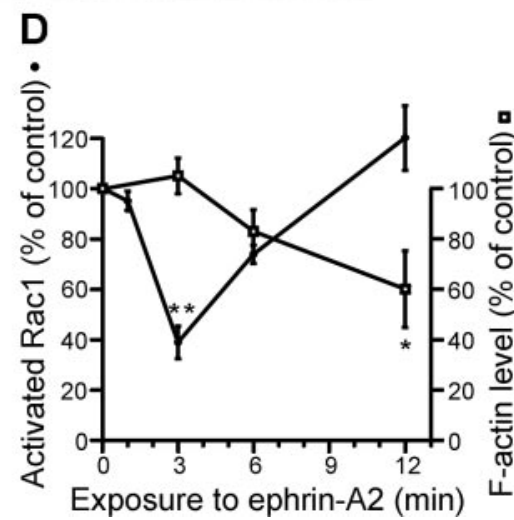

Figure 1. Ephrin-A2 collapses growth cones of axons from the temporal side of the retina and alters Rac1 activity. $A$, Time-lapse sequence of a growth cone before $(-1 \mathrm{~min})$ and after treatment with $1.0 \mu \mathrm{g} / \mathrm{ml}$ ephrin-A2 $(+1$ to $+12 \mathrm{~min})$. Note that growth cone collapse, as evidenced by loss of lamellipodia and filopodia, was evident at $6 \mathrm{~min}$ after addition of ephrin-A2 and that the axon had retracted significantly by 12 min after treatment. $B$, Immunoblot showing levels of activated Rac1 in retina at various times after ephrin treatment. Dissociated cells from temporal retina were treated with $1.0 \mu \mathrm{g} / \mathrm{ml}$ ephrin-A2 for 1-12 min. GTP-bound Rac1 was affinity purified from lysed cells using the Rac1binding domain of p21-activated kinase 1. NT, No treatment. $C$, Quantification of Rac1 activity levels as a function of time after treatment with ephrin-A2. Rac1 activity is expressed as percentage of the activity of untreated cells. At 3 min after ephrin-A2 treatment, Rac1 activity was reduced but returned to baseline levels by $6-12 \mathrm{~min}$. The time course of retinal growth cone collapse is shown relative to changes in Rac1 activity levels. $D$, Quantification of growth cone F-actin content as a function of time after treatment with ephrin-A2. F-actin levels are normalized to data from untreated growth cones. Growth cone F-actin content was significantly reduced after 12 min of treatment with ephrin. The time course of Rac1 inactivation is reproduced from that in $C$ to allow a direct comparison of the two variables. Significant difference from control: ${ }^{*} p<0.01 ;{ }^{* *} p<0.001$. centrations of Rac1 inhibitory peptide up to $4 \mu \mathrm{g} / \mathrm{ml}$ allowed lamellipodial and filopodial activity comparable with controls (Fig. 2A,C). Treatment of cultures with concentrations of peptide from 8 to $10 \mu \mathrm{g} / \mathrm{ml}$, however, inhibited lamellipodial and filopodial activity in the majority of growth cones, and concentrations of $>10 \mu \mathrm{g} / \mathrm{ml}$ blocked all filopodial and lamellipodial activity within 30 min of treatment (data not shown). Consistent with the proposed role of Rac1 in regulating formation of lamellipodia (Hall, 1998), at the higher peptide concentrations, growth cones were immotile with a mostly diminished lamellipodial area but with an increase in the number of filopodia. Grow th cone collapse was not observed in response to peptide treatment at any of the concentrations tested. These data suggest that the reduction of Rac1 activity after ephrin-A2 treatment is not directly responsible for the subsequent collapse of retinal growth cones.

Growth cone collapse is believed to depend on changes in the dynamics and organization of the actin cytoskeleton (Korey and van Vactor, 2000). The actin cytoskeleton in growth cones of retinal axons was examined after ephrin-A2 treatment. Retinal cultures, treated with ephrin-A2 for 1-12 min or untreated, were fixed and stained with rhodamine-phalloidin to label F-actin. The growth cones were visualized by fluorescence microscopy, and the fluorescence intensity was quantified. The F-actin content of growth cones was not different from that of controls during the first $6 \mathrm{~min}$ of ephrin treatment. Before treatment with ephrin,
F-actin was concentrated in filopodia and lamellipodia, with moderate levels in the central domain of the growth cone (Fig. $2 B$ ). From 6 to $12 \mathrm{~min}$ after addition of ephrin, F-actin levels decreased $40 \%$ (Fig. 1D). As the growth cones collapsed in response to ephrin, the F-actin reorganized. It became concentrated in the central domain and then in the swelling at the distal tip of the fully collapsed growth cone, an F-actin organization that we refer to as the "collapse bulb" (Fig. 2B, bottom left panel). Thus, ephrin-induced depolymerization and reorganization of F-actin in growth cones correlate with the resumption of Rac1 activity rather than with the initial transient reduction in the level of activated Rac1.

We next asked whether Rac1 activity is required for collapse of retinal growth cones in response to ephrin. Retinal cultures were treated with the Rac1 inhibitory peptide $(0.5-2.0 \mu \mathrm{g} / \mathrm{ml})$ for $1 \mathrm{hr}$ before exposure to ephrin-A2. The Rac1 inhibitory peptide inhibited ephrin-induced growth cone collapse in a dose-dependent manner (Fig. 2A,C). Although growth cones pretreated with the Rac1 inhibitory peptide did not collapse in response to ephrinA2, growth cones became immotile but retained lamellipodia and filopodia. Note the lack of shape change between 6 and $15 \mathrm{~min}$ after ephrin-A 2 treatment in Figure $2 A$. In control experiments, cultures were treated first with $2.0 \mu \mathrm{g} / \mathrm{ml}$ inhibitory peptide and then with cytochalasin D, a drug that stops actin filament assembly and causes growth cone collapse. The inhibitory peptide did 


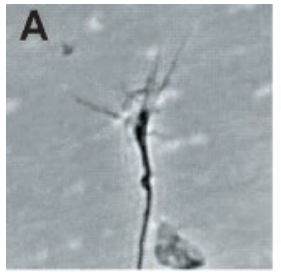

0 min rac inhib pep

B
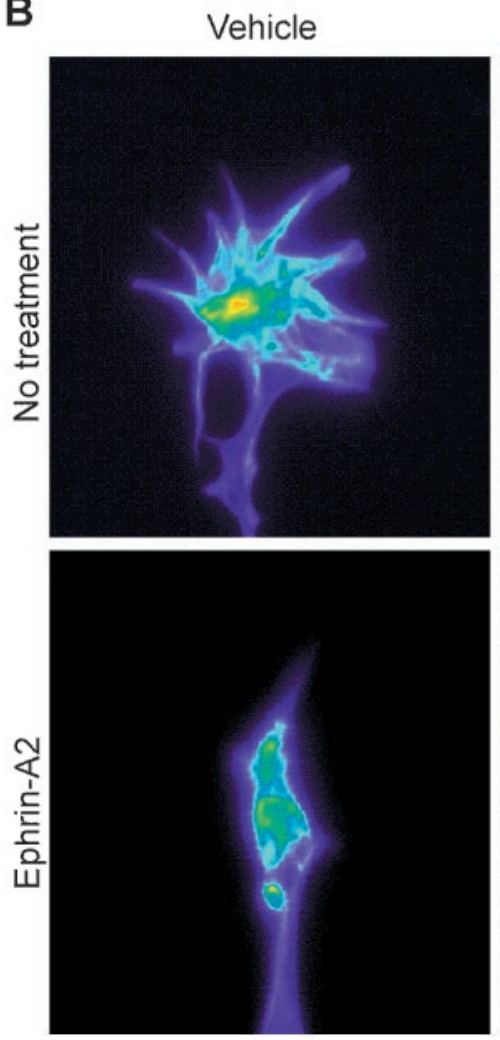

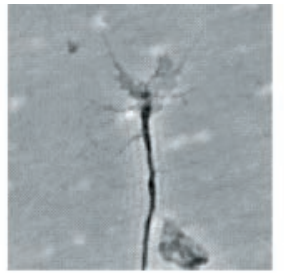

$30 \mathrm{~min}$ rac inhib pep

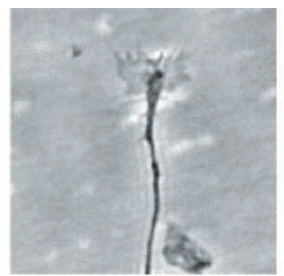

$60 \mathrm{~min}$ rac inhib pep

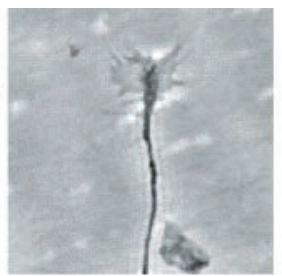

3 min ephrin rac inhib pep

C

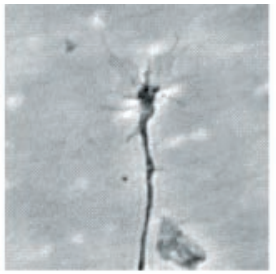

6 min ephrin rac inhib pep

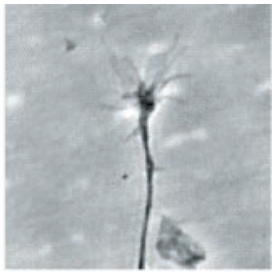

15 min ephrin rac inhib pep

Rac inhib pep
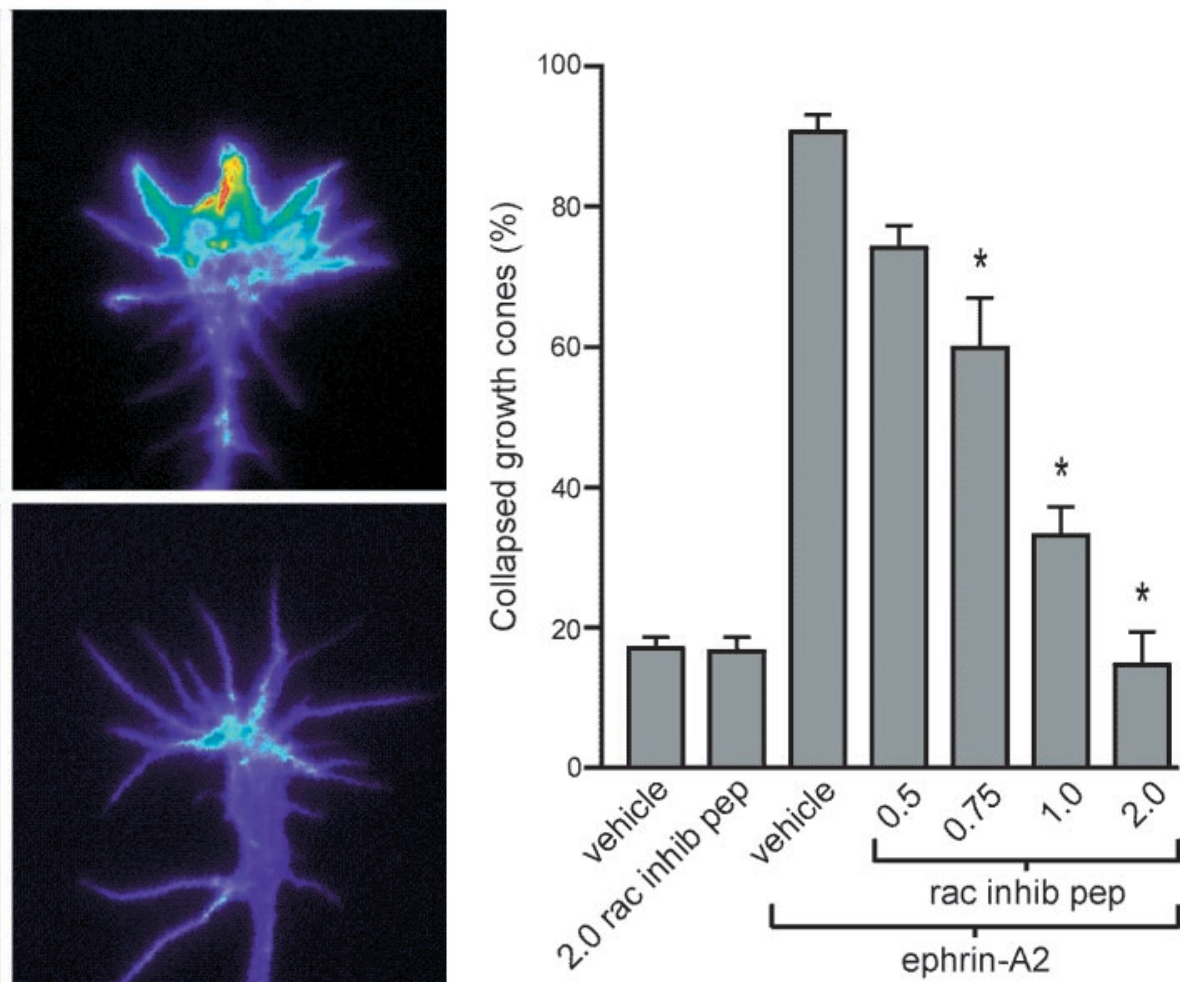

Figure 2. Rac1 is required for ephrin-A2-induced growth cone collapse. $A$, Time-lapse sequence of a retinal growth cone treated first with $2.0 \mu \mathrm{g} / \mathrm{ml}$ Rac1 inhibitory peptide $(0 \mathrm{~min}-60 \mathrm{~min} ; \mathrm{rac}$ inhib pep $)$ and then with $1.0 \mu \mathrm{g} / \mathrm{ml}$ ephrin-A2 for $15 \mathrm{~min}$. B, Pseudocolor images of retinal growth cones stained with rhodamine-phalloidin to reveal F-actin. All images were acquired using identical acquisition parameters. Warmer colors indicate higher levels of actin. Treatment with the Rac1 inhibitory peptide $(1 \mathrm{hr}, 2.0 \mu \mathrm{g} / \mathrm{ml})$ did not alter F-actin levels or organization in growth cones. Treatment with ephrin-A2 (12 min, $1.0 \mu \mathrm{g} / \mathrm{ml})$ caused F-actin to depolymerize and aggregate in the distal axon, a structure that we refer to as the collapse bulb. Treatment with Rac1 inhibitory peptide first, followed by addition of ephrin-A2, resulted in levels of F-actin in the growth cone that were similar to those seen in the growth cones treated with ephrin-A2 alone. However, F-actin did not reorganize into a collapse bulb. $C$, Quantification of Rac1 inhibitory peptide treatments and growth cone response to ephrin-A2. The Rac1 inhibitory peptide blocked ephrin-induced growth cone collapse in a dose-dependent manner. Growth cones were treated with the peptide for $1 \mathrm{hr}$ before ephrin-A2 treatment. Significant difference from culture without inhibitory peptide treated with ephrin: * $p<0.001$.

not block cytochalasin D-induced growth cone collapse, indicating specificity in its effect on ephrin-A2-mediated growth cone collapse (data not shown). The effect of the Rac1 inhibitory peptide and ephrin treatments on growth cone F-actin was also examined. Retinal explants were treated with vehicle or inhibitory peptide for $1 \mathrm{hr}$, followed by a $15 \mathrm{~min}$ exposure to vehicle or ephrin-A2. Treatment with concentrations of the Rac1 inhibitory peptide that completely blocked ephrin-induced growth cone collapse $(2 \mu \mathrm{g} / \mathrm{ml})$ had no effect on growth cone F-actin levels or organization (Fig. $2 B)(p>0.5)$. Treatment with a high concentration of inhibitory peptide $(8 \mu \mathrm{g} / \mathrm{ml})$, which blocks growth cone motility, caused a $25 \pm 3 \%$ decrease in F-actin $(p<0.003$ compared with vehicle). A $12 \mathrm{~min}$ treatment with ephrin-A2 caused a $64 \pm 10 \%$ decrease in growth cone F-actin levels compared with vehicle alone $(p<0.00001)$. Surprisingly, there was a similar reduction in F-actin levels in growth cones treated with both the Rac1 inhibitory peptide and ephrin-A2 (57 $\pm 8 \%$; $p>0.3$ ). Thus, Rac1 inhibition did not prevent the loss of F-actin in response to ephrin-A2, although growth cone collapse was blocked. Inhibition of Rac1 activity, however, prevented ephrinA2-induced reorganization of F-actin into a collapse bulb. In the presence of the Rac1 inhibitory peptide after ephrin-A2 treatment, F-actin remained evenly distributed throughout the growth cone (Fig. 2B). These data indicate that Rac1 is required for ephrin-A2-induced growth cone collapse in a manner that is independent of reduction in F-actin levels.

Reduction in Rac1 expression was used as an alternative to the Rac1 inhibitory peptide as an additional test of the role of Rac1 


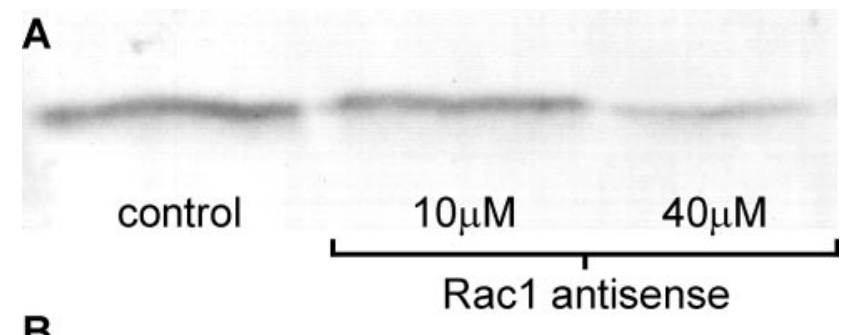

B

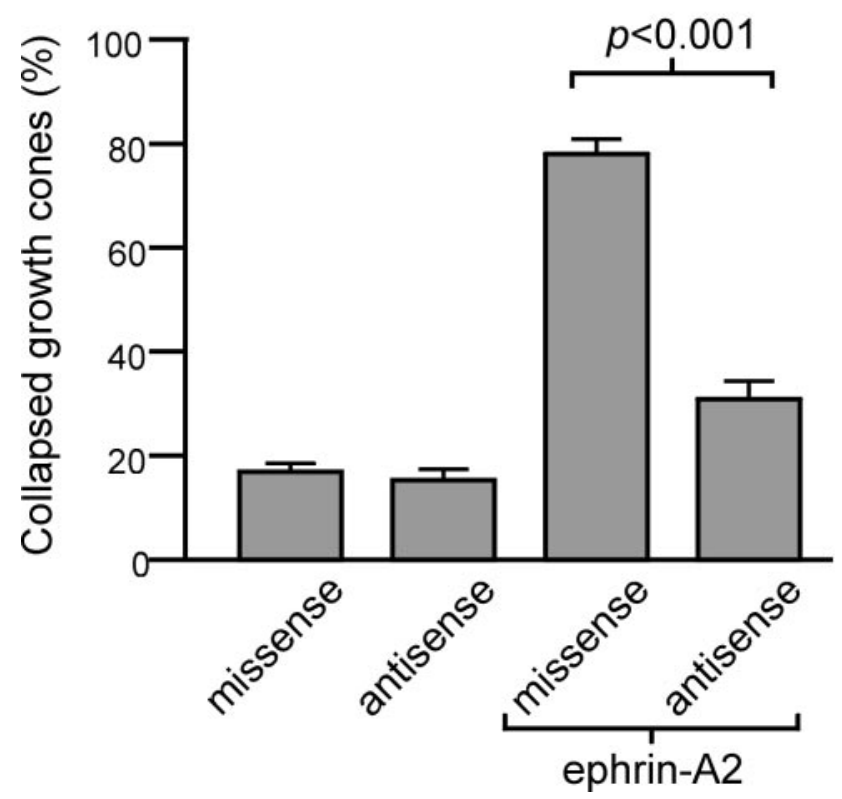

Figure 3. Reduction of Rac1 protein level using an antisense oligonucleotide inhibits ephrin-A2-induced growth cone collapse. $A$, Immunoblot showing levels of Rac1 after oligonucleotide treatment. Rac1 antisense treatment reduced the expression of Rac1 protein. Dissociated cells from the temporal side of the retina were cultured in the presence of $40 \mu \mathrm{M}$ missense control or 10-40 $\mu \mathrm{M}$ Rac1 antisense oligonucleotides for $24 \mathrm{hr}$. $B$, Quantification of growth cone collapse in oligonucleotide-treated cultures. Reduction of Rac1 expression inhibits the ability of ephrin-A2 to induce growth cone collapse. Temporal retinal explants were cultured for $24 \mathrm{hr}$ in the presence of missense or Rac1 antisense oligonucleotides and then treated with $1.0 \mu \mathrm{g} / \mathrm{ml}$ ephrin-A2 for $15 \mathrm{~min}$.

in ephrin-induced growth cone collapse. A Rac1-specific antisense oligonucleotide, previously used in rat (Dorseuil et al., 1992), was modified for use in chick. The efficacy of the Rac1 antisense for reducing Rac1 expression in developing chick retina was tested. Dissociated temporal retinal cells were cultured overnight in the presence of Rac1 antisense or control missense oligonucleotides. On the basis of densitometry analysis of immunoblots, Rac1 expression was reduced $56 \%$ after treatment with $40 \mu \mathrm{M}$ Rac1 antisense (Fig. $3 A$ ), an effect similar to that seen previously (Dorseuil et al., 1992). Neurite outgrowth from Rac1 antisense-treated explants appeared normal, with no alteration in growth cone appearance or in the percentage of collapsed growth cones (Fig. 3B). There were, however, slight reductions in the average axon length and in the number of axons per explant compared with missense-treated explants or untreated controls (data not shown). Reduction of Rac1 expression significantly decreased the percentage of growth cones that collapsed in response to ephrin-A2 (Fig. 3B). There was no significant difference in the percentage of growth cones that collapsed between control cultures and cultures treated with Rac1 antisense and ephrin-A2 $(p>0.05)$. Thus, reducing expression of Rac1 decreased the ability of retinal axons to respond to ephrin-A2 in vitro. This confirms the results obtained with the Rac1 inhibitory peptide.

The next aim was to determine the effect of increased Rac1 activity on the response of growth cones to ephrin-A2. We attempted to infect retinal ganglion cells with an adenovirus construct expressing constitutively active Rac1. Consistent with a previous report (Yamagata et al., 1994), chick retinal ganglion cells were not reliably infected by adenovirus; therefore, DRG neurons were used. It was first necessary to compare DRG growth cones with retinal growth cones with regard to their response to ephrin-A2 and the role of Rac1. Neurotrophins are required for DRG survival and maturation. DRG explants, cultured in one of three neurotrophins, were exposed for 15 min to ephrin-A2 (Fig. $4 A$ ). Ephrin-A2 collapsed the growth cones of DRG neurons raised in NGF, neurotrophin-3, and BDNF. Because BDNFresponsive DRG neurons were most responsive to ephrin-A2, subsequent experiments were performed on DRG neurons raised in BDNF. DRG explant cultures were treated for $1 \mathrm{hr}$ with vehicle or Rac1 inhibitory peptide $(2.0 \mu \mathrm{g} / \mathrm{ml})$ and then exposed to vehicle or ephrin-A2 for $15 \mathrm{~min}$. The Rac1 inhibitory peptide blocked ephrin-induced growth cone collapse (Fig. 4B). Thus, as with retinal cultures, Rac1 activity is required for DRG growth cones to collapse in response to ephrin-A2.

To determine the effect of increased levels of Rac1 activity on the response of growth cones to ephrin-A2, dissociated DRG neurons were infected with an adenovirus that carries a gene for a constitutively active form of Rac1A (V12Rac1A; Kuhn et al., 1999). The percentage of spontaneously collapsed growth cones was not affected by expression of V12Rac1 relative to neurons infected with a control adenovirus expressing lacZ (Fig. 4C). Under control conditions, DRG growth cones were filopodial. Expression of V12Rac1 increased the percentage of growth cones exhibiting lamellipodia by $26 \%(p<0.02$; two-tailed $t$ test; $n=6$ cultures in each group). In agreement with previous findings (Kuhn et al., 1999), expression of V12Rac1 increased the mean F-actin content of growth cones by $23 \%$ relative to control infected neurons ( $p<0.01$; two-tailed $t$ test; $n>30$ growth cones in each group). Expression of constitutively active Rac1A, however, did not inhibit the collapse of DRG growth cones in response to ephrin-A2 (Fig. 4C). This indicates that although Rac1 activity is required for ephrin-induced growth cone collapse, a nonspecific increase in Rac1 activity is not sufficient to alter growth cone response to ephrin.

It was shown previously that growth cone collapse in response to semaphorin 3A and ephrin-A5 correlates with increased rates of membrane internalization via endocytosis (Fournier et al., 2000). Therefore, we asked whether Rac1 mediates endocytosis in response to ephrin-A2. The time course of endocytosis in growth cones exposed to ephrin-A2 was examined. The uptake of extracellularly applied rhodamine-labeled dextran was used to monitor endocytosis. Retinal growth cones were simultaneously treated with ephrin-A2 and dextran and then fixed at 3, 6, and 12 min after treatment. Rhodamine-labeled vesicles were counted in the distal $20 \mu \mathrm{m}$ of axons. Increased endocytosis in retinal growth cones after ephrin-A2 treatment correlated with the resumption of Rac1 activity (Fig. 5A). Ephrin-A2 treatment also increased the number of dextran-labeled vesicles in DRG growth cones (Fig. 5D). A $1 \mathrm{hr}$ pretreatment with the Rac1 inhibitory peptide blocked the ephrin-A2-induced increase in endocytosis in retinal and DRG growth cones (Fig. $5 B-D$ ). To rule out the possibility that inhibition of Rac1 was blocking endocytosis in general, the 


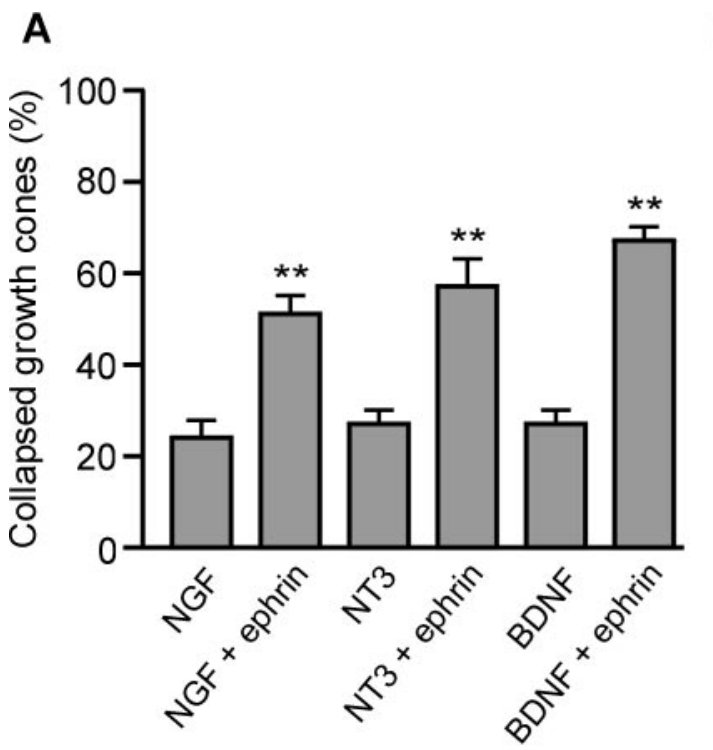

B

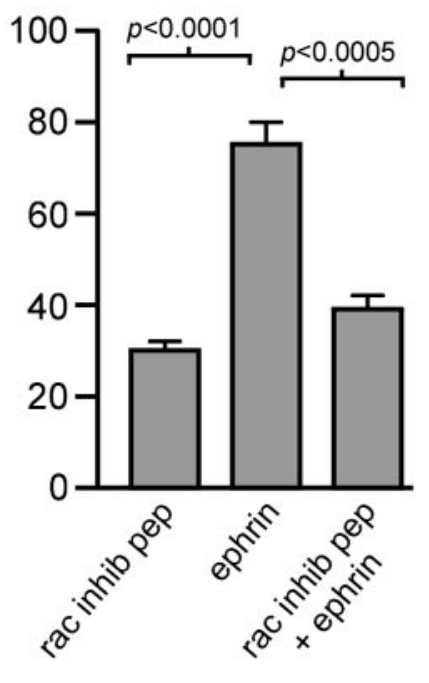

C

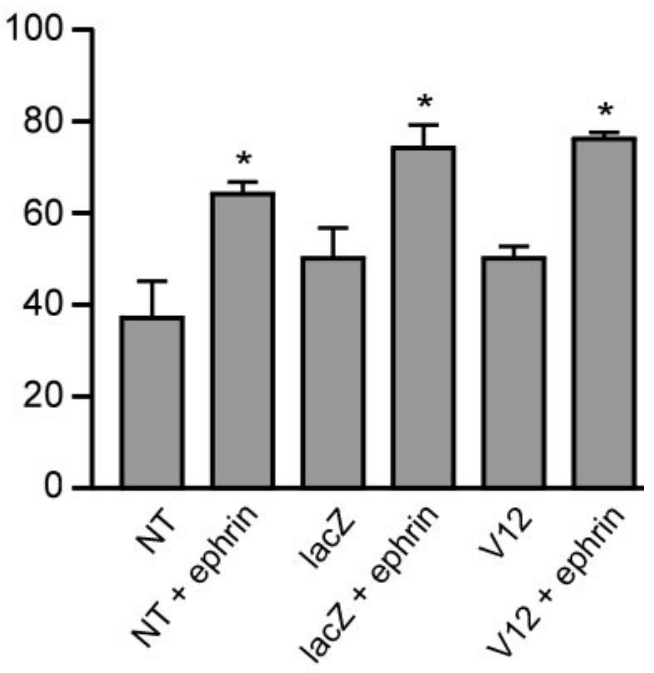

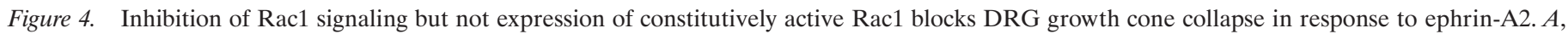

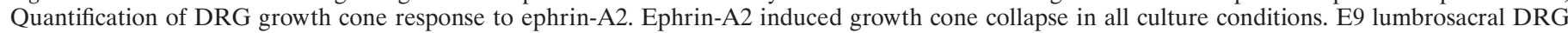

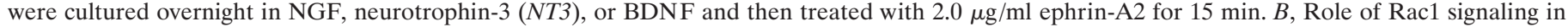

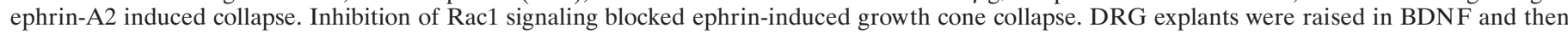

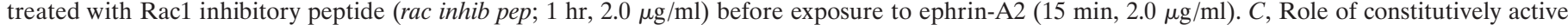

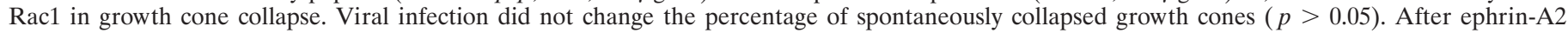

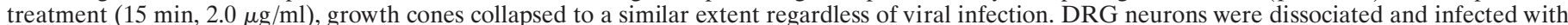

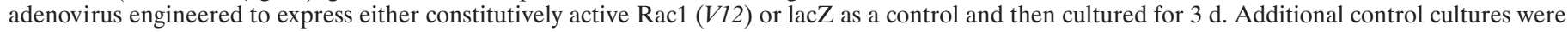

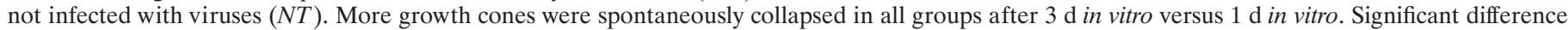
form control: ${ }^{*} p<0.05 ;{ }^{*} p<0.01$.

effect of the Rac1 inhibitory peptide on constitutive endocytosis was examined. Treatment with the peptide at a concentration that fully blocked ephrin-A2-induced endocytosis had no effect on constitutive endocytosis in retinal or DRG growth cones (Fig. $5 C, D)$. These data suggest that Rac1 is required for ephrin-A2induced endocytosis in growth cones but is not required for constitutive endocytosis.

The role of F-actin during ephrin-A2-induced endocytosis was investigated. Growth cone collapse induced by the F-actindepolymerizing drugs cytochalasin $\mathrm{D}$ and latrunculin-A did not exhibit increased rates of endocytosis (Table 1), as shown previously (Fournier et al., 2000). Thus, increased endocytotic activity is not simply a response to F-actin depolymerization during growth cone collapse. Although F-actin depolymerization does not induce endocytosis, it is possible that $\mathrm{F}$-actin is required for ephrin-A2-induced endocytosis. Neither cytochalasin D nor latrunculin-A, however, inhibited ephrin-A2-induced endocytosis in retinal ganglion cell growth cones. Retinal cultures were pretreated with actin-depolymerizing drugs for 5 min before treatment with ephrin-A2. Although growth cones were collapsed by treatment with cytochalasin D or latrunculin-A, ephrin-A2 stimulated endocytosis to an extent similar to that seen in control growth cones (Table 1). This demonstrates that ephrin-A2 can induce endocytosis independent of changes in growth cone morphology, and that F-actin is not required for ephrin-A2-induced endocytosis.

We confirmed the results obtained using the Rac1 inhibitory peptide by loading a dominant negative form of Rac1 (N17Rac1) into the growth cones of axons growing from explants of temporal retina in vitro. Control growth cones were loaded with bovine serum albumin. N17Rac1 or albumin was loaded into growth cones using the Chariot peptide. After a 12 min treatment with 1 $\mu \mathrm{g} / \mathrm{ml}$ ephrin-A2, $62 \%$ of growth cones were collapsed in control cultures, compared with only $25 \%$ on N17Rac1-loaded cultures. After ephrin-A2 treatment, F-actin levels in growth cones decreased by $52 \%(p<0.0001)$ and $48 \%(p<0.0001)$ in control and N17Rac1-loaded growth cones, respectively. In control cultures, ephrin-A2 induced a $240 \%$ increase in the number of endocytotic vesicles present in growth cones $(p<0.00001)$, compared with an $18 \%$ increase in N17Rac1-loaded growth cones $(p>0.1)$. N17Rac1 did not affect constitutive endocytosis (data not shown). Therefore, inhibition of Rac1 signaling using either N17Rac1 or the Rac1 inhibitory peptide had similar effects on ephrin-A2 signaling in growth cones.

Rac1 activity also is required for semaphorin 3A-induced growth cone collapse (Jin and Strittmatter, 1997; Kuhn et al., 1999; Vastrik et al., 1999). The effect of Rac1 inhibition on endocytosis during growth cone collapse in response to semaphorin $3 \mathrm{~A}$ was examined. DRG explants were treated with medium conditioned by 293 cells engineered to express semaphorin 3A. As shown previously (Vastrik et al., 1999), treatment with the Rac1 inhibitory peptide blocked semaphorin 3A-induced growth cone collapse (data not shown). The Rac1 inhibitory peptide also inhibited semaphorin 3A-induced endocytosis (Fig. 5D). Therefore, Rac1 mediates ligand-induced endocytosis of the growth cone plasma membrane during collapse induced by both ephrin-A2 and semaphorin $3 \mathrm{~A}$.

Finally, we asked whether Rac1 plays a role in development of the topography of the retinotectal projection in vivo. Development of normal topography is thought to depend on the response of growing retinal axons to ephrins expressed by tectal cells (Flanagan and Vanderhaeghen, 1998; O'Leary et al., 1999; Wilkinson, 2000). We found previously that injection into the developing eye of an antisense oligonucleotide targeting EphA3, 
A

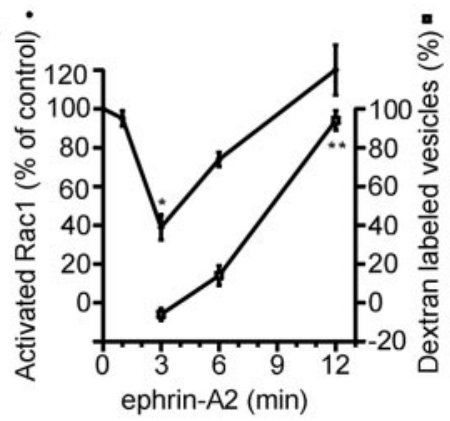

C

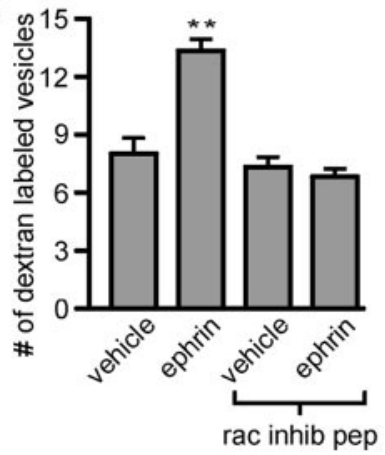

D

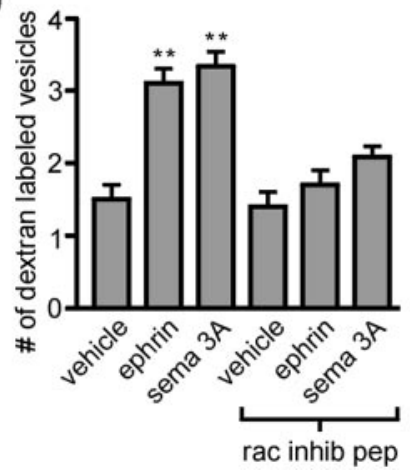

B
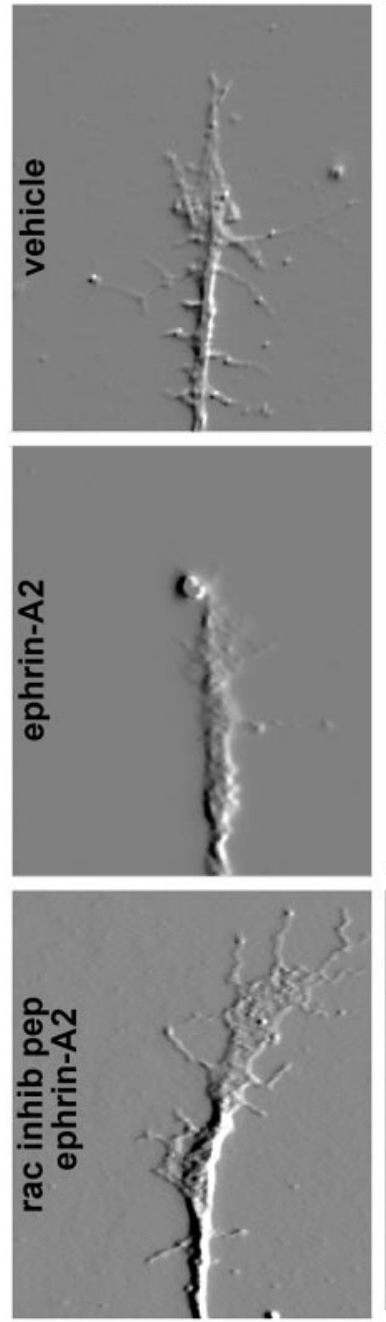

Dextran
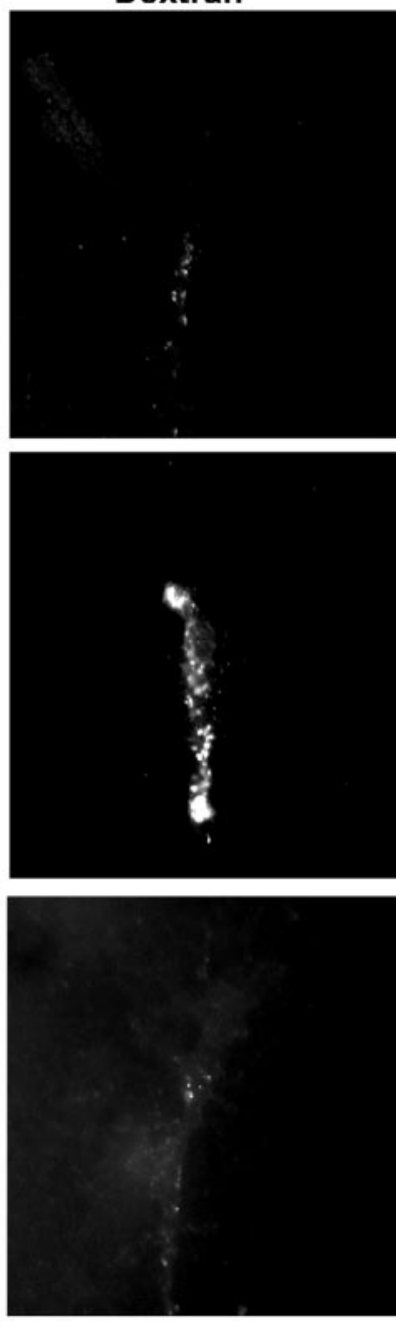

Figure 5. Ephrin-A2 and semaphorin $3 \mathrm{~A}$ induce endocytosis of the growth cone plasma membrane in a Rac1dependent manner. $A$, Endocytosis of labeled dextran after ephrin-A2 treatment. Endocytotic activity was elevated at 12 min after treatment with ephrin-A2. The time course of changes in Rac1 activity is reproduced from Figure $1 C$ to allow a direct comparison. Retinal growth cones were treated with ephrin-A2 plus 2.5 $\mathrm{mg} / \mathrm{ml}$ rhodamine-labeled dextran for 3-12 min. The number of dextrancontaining vesicles in the distal $20 \mu \mathrm{m}$ of axons was then counted ( 3 experiments with $>80$ growth cones sampled at each time point). The increase in dextran labeling is expressed relative to the number of dextran-labeled vesicles in timematched controls treated with dextran alone. B, Role of Rac1 in ephrin-A2 induced endocytosis. A $12 \mathrm{~min}$ treatment with $1.0 \mu \mathrm{g} / \mathrm{ml}$ ephrin-A2 resulted in a large increase in the number of endocytotic vesicles in the distal tip of axons compared with those in cultures treated with vehicle alone. Inhibition of Rac1 signaling prevented the increase in endocytotic vesicles in response to ephrin-A2. Staining the membrane with $\mathrm{DiO}$ showed retinal growth cone morphology, and endocytosis was revealed by accumulation of rhodamine-labeled dextran. All images were obtained using identical acquisition parameters. The $\mathrm{DiO}$ images were embossed to better reveal growth cone morphology. $C$, Quantification of endocytosis in retinal growth cones. Ephrin-A2 significantly increased endocytosis in the distal $20 \mu \mathrm{m}$ of retinal axons, and the Rac1 inhibitory peptide (rac inhib pep) blocked the effects of ephrin-A2 on endocytosis. Treatment with the Rac1 inhibitory peptide alone did not alter the number of dextran-labeled vesicles $(p>0.5) . D$,

Quantification of endocytosis in DRG growth cones. As with retinal ganglion cells, ephrin-A2 increased the number of dextran-labeled vesicles, and the Rac1 inhibitory peptide blocked the effect of ephrin-A2. Similarly, a 30 min exposure to semaphorin $3 \mathrm{~A}$ (sema $3 A$ ) increased the number of dextran-labeled vesicles in a Rac1-dependent manner. Treatment with the Rac1 peptide did not affect basal endocytosis $(p>0.5)$. Differences in absolute number of dextran-labeled vesicles between retinal and DRG growth cones likely reflect a difference in growth cone size, DRG growth cones being significantly smaller. Significant difference from control: * $p<0.001 ; * * p<0.0001$.

\section{Table 1. Role of F-actin in ephrin-A2 induced endocytosis}

Treatment

Number of dextranlabeled vesicles $(n)$

Vehicle (DMSO)

$4.9 \pm 0.5(84)$

$5.5 \pm 0.6(82)$

$4.3 \pm 0.5(89)$

$11.1 \pm 0.9(76)^{*}$

$10.1 \pm 0.8(87)^{*}$

$9.1 \pm 0.8(80)^{*}$ otide to Rac1 would mimic the effects of reduced EphA3 expression. A Rac1 antisense or a missense oligonucleotide was injected into one eye of chick embryos at E6, an age by which retinal axons had reached the tectum. A second oligonucleotide injection was made into the same eye on E8. On E10, a small injection of a retrograde axon tracer, DiI, was made into the posterior tectum contralateral to the oligonucleotide-injected eye. Twenty-four hours later, the oligonucleotide-treated retinas were prepared as flat mounts. Also, the injection site in the tectum was mapped, and the brains were sectioned and processed for immunohistochemistry with an antibody that labels retinal axons, RA4. Qualitatively, the appearance of RA4 staining in the tectum was not altered by treatment with Rac1 antisense oligonucleotides (Fig. $6 A$ ), indicating that extension of retinal axons across the tectum was not affected by the antisense treatment. Treatment with the missense (control) oligonucleotide resulted in a normal pattern of retrogradely labeled cells in the injected retinas, indicating that their axons were correctly targeted in the tectum (six of six embryos) (Fig. 6B). Thousands of labeled ganglions were concentrated in a discrete area on the nasal side of the retina. Also, a receptor for ephrin-A2, altered the topography of the retinotectal projection (W. M. Jurney, D. J. Selski, and S. C. McLoon, unpublished results). In the present study, we tested whether treatment of the developing retina with an antisense oligonucle-
Retinal growth cone collapse induced by F-actin depolymerizing drugs did not increase endocy tosis compared with vehicle alone $(p>0.05)$. Addition of ephrin-A2 in a significant increase in endocytosis in all conditions examined.

*Significant differences compared with identical cultures without ephrin $(p<$ $0.001)$. 

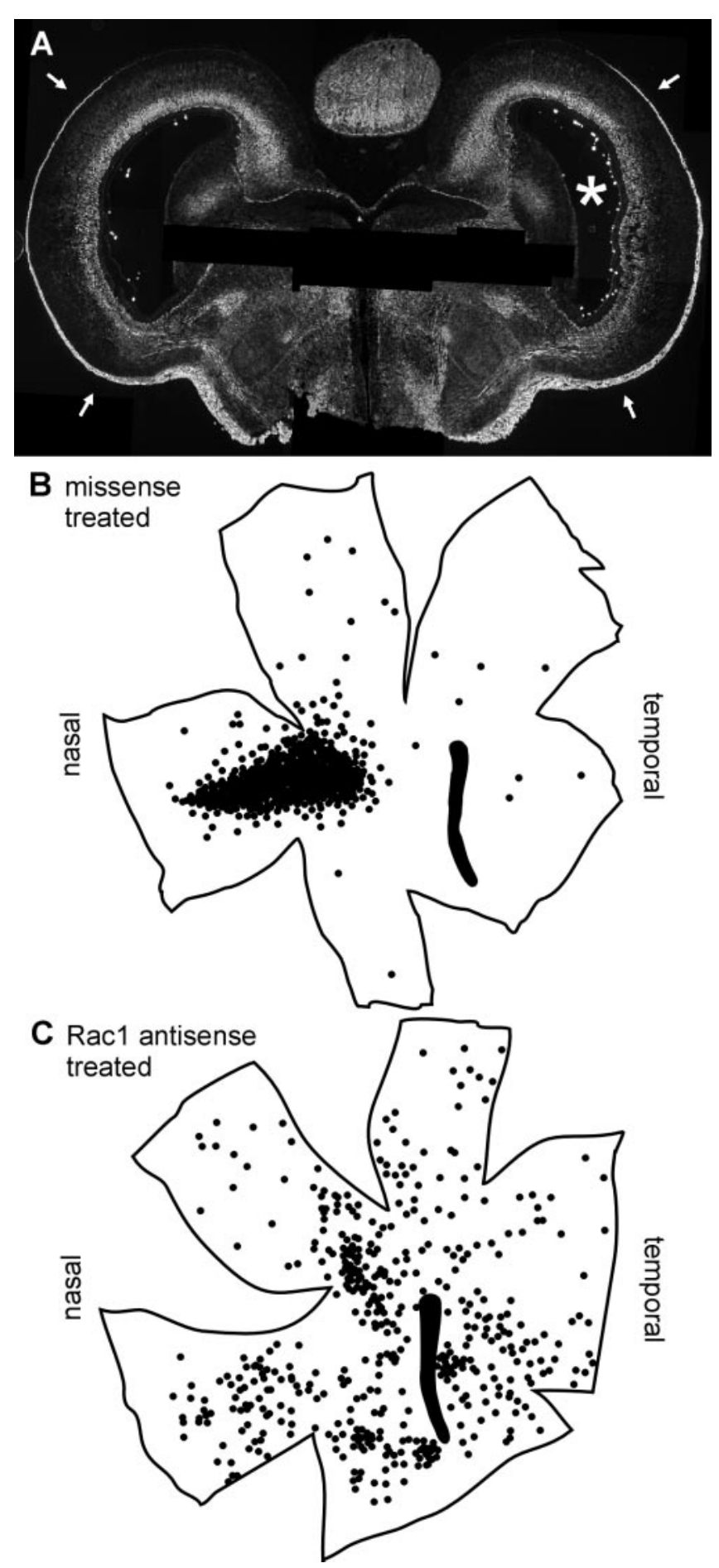

Figure 6. Rac1 activity is required for normal development of retinotectal topography in vivo. Rac1 antisense or missense oligonucleotide was injected into one eye of chick embryos on E6 and E8. On E10, a retrogradely transported axon tracer, DiI, was injected into the posterior portion of the optic tectum contralateral to the oligonucleotide-treated eye. Embryos were fixed on E11. $A$, Coronal section from the brain of a Rac1 antisense-treated embryo stained with an antibody that labels retinal axons. The asterisk denotes the optic tectum contralateral to the Rac1 antisense-injected eye. Arrows point to stained retinal axons in the optic fiber layer. Rac1 antisense treatment did not inhibit retinal axon growth across the tectum. $B, C$, Tracings of the outlines of flat mounted-retinas injected with missense $(B)$ or Rac1 antisense $(C)$ oligonucleotide. Dots represent retrogradely labeled cells. In the retina injected with the Rac1 antisense oligonucleotide, no organized topography could be distinguished. a few isolated labeled cells were scattered across the retina, which is normal at this early stage of development (Wu et al., 2001). In contrast, in most retinas injected with the Rac1 antisense oligonucleotide, no organized topography could be distinguished ( 7 of 11 embryos) (Fig. 6C). DiI-labeled cells were broadly distributed across these retinas. There were typically several concentrations of labeled cells, but most of these were not in the topographically appropriate region. In other antisense-treated embryos, there was a concentration of retrogradely labeled cells in the topographically appropriate region, but there was also a higher number of labeled cells scattered across the retina than ever encountered in control embryos, which may represent a partial effect (2 of 11 embryos). Some antisense-treated embryos appeared to have a normal topography, which could have been attributable to technical problems with the injections ( 2 of 11 embryos). The effects of the Rac1 antisense treatment are similar to the effects observed after treatment with the EphA3 antisense oligonucleotide. These findings are consistent with the suggestion that Rac1 is a required downstream effector of Eph-ephrin signaling in vivo and is required for development of normal retinotectal topography.

\section{DISCUSSION}

The major aim of this study was to understand the cytoplasmic signaling that links negative guidance molecules such as ephrin-A2 and semaphorin 3A to collapse of the growth cone at the leading end of growing axons. The small GTPase Rac1 is essential for growth cone collapse in response to ephrin-A2 and semaphorin 3A. Interfering with Rac1 signaling with a competitive peptide, a dominant negative Rac1 or antisense oligonucleotides blocked collapse of growth cones in response to ephrin-A2. This is consistent with previous studies that blocked semaphorin 3A-induced growth cone collapse using dominant negative Rac1 mutants (Jin and Strittmatter, 1997; Kuhn et al., 1999). Dominant negative Rac1 mutants, however, did not block collapse induced by either lysophosphatidic acid or myelin. Apparently, there are at least two mechanisms of externally induced growth cone collapse, only one of which appears to require Rac1 activity.

Rac1 activity transiently decreases in response to ephrin-A2, but this decrease does not appear to be essential for growth cone collapse. Three minutes after ephrin-A2 exposure, Rac1 activity was reduced to $40 \%$ of the control level. This reduction was transient, because Rac1 activity returned to control levels by 12 min after ephrin-A2 treatment. Interestingly, growth cone collapse occurred during the period when Rac1 activity was increasing to baseline levels. These observations demonstrate that growth cone collapse is not mediated by activation of Rac1 above control levels. A reduction of Rac1 activity in neurons in response to ephrin-A5 was reported previously (Wahl et al., 2000). In that study, however, Rac1 activity was examined at a single time point after treatment with ephrin-A5, and the subsequent recovery in Rac1 activity was not observed or correlated temporally with growth cone collapse. Although growth cone collapse is preceded by a reduction in Rac1 activation, experimental reduction of Rac1 activity by interfering with its signaling pathway or with its expression did not cause growth cone collapse. Similarly, expression of dominant negative Rac1 did not cause growth cone collapse (Jin and Strittmatter, 1997; Kuhn et al., 1999). Thus, the inactivation of Rac1 activity does not appear to be sufficient for growth cone collapse. The nature of the transient inactivation of Rac1 after ephrin treatment is not clear. The inactivation could reflect a rapid loss of Rac1 associated with axon extension. The subsequent reactivation could reflect a slower increase in Rac1 


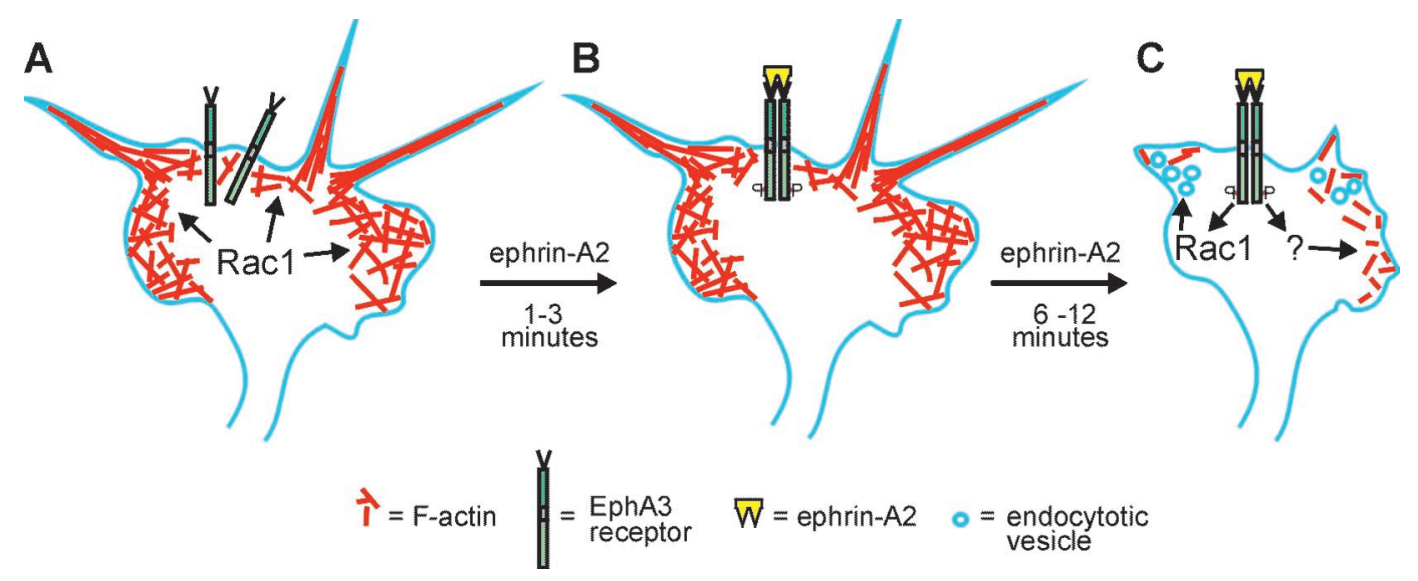

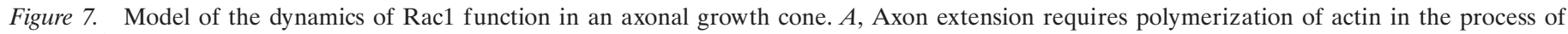

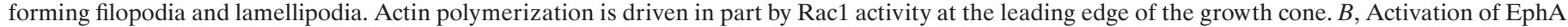

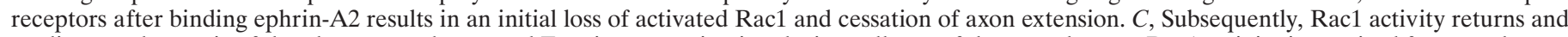

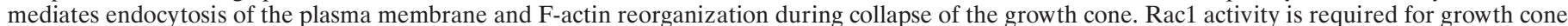
collapse. Growth cone collapse also involves depolymerization of F-actin, a process that is independent of Rac1 activity.

activation associated with processes underlying growth cone collapse. These observations suggest that ephrins do not stimulate Rac1 activity per se but rather switch the function of Rac1 into a pathway that promotes growth cone collapse.

Although Rac1 activity is required for ephrin-A2-induced growth cone collapse, increased Rac1 activity is not in itself sufficient to induce growth cone collapse. Expression of constitutively active Rac1 did not affect either basal rates of growth cone collapse or collapse in response to ephrin-A2. Although constitutively active Rac1 also had no effect on semaphorin 3Ainduced growth cone collapse, it did block the ability of myelin to induce growth cone collapse (Jin and Strittmatter, 1997; Kuhn et al., 1999). Rac1 probably requires other factors activated by ephrin or semaphorin $3 \mathrm{~A}$ to bring about collapse. It is also possible that ephrin-induced targeting of activated Rac1 is important in collapse, and constitutively active Rac1 is not targeted appropriately.

Growth cone collapse in response to ephrin involves F-actin depolymerization. Although inhibition of Rac1 signaling blocked ephrin-A2-induced collapse, it did not block F-actin depolymerization. These data have two implications: first, Rac1 does not regulate actin depolymerization after ephrin treatment; and second, ephrin-induced actin depolymerization is not sufficient to induce growth cone collapse. Semaphorin 3A also causes growth cone F-actin depolymerization and has been shown to phosphorylate the actin-depolymerizing factor cofilin through the action of LIM-kinase (Yang et al., 1998; Aizawa et al., 2001), which is activated by both Rac1 and RhoA effectors (Edwards et al., 1999; Maekawa et al., 1999). Because ephrin-A5 is known to activate RhoA and Rho-kinase (Wahl et al., 2000), it is possible that ephrins depolymerize actin during growth cone collapse via a pathway that includes RhoA, Rho-kinase, LIM-kinase, and cofilin, independent of Rac1.

F-actin organization is the major determinant of growth cone morphology (Letourneau, 1996; Baas and Luo, 2001). In control cultures, ephrin-A2 caused depolymerization of $40 \%$ of the $\mathrm{F}$-actin, whereas the remaining F-actin became concentrated in the center of the collapsing growth cone. When Rac1 activity was inhibited, F-actin failed to undergo this reorganization but rather was found throughout the lamellipodia and filopodia. Therefore, the lack of growth cone collapse when Rac1 activity was inhibited correlates with the failure of F-actin to undergo reorganization. Although during normal axon growth, Rac1 drives the formation of the F-actin meshwork in lamellipodia (Kuhn et al., 2000), these observations suggest that during growth cone collapse, Rac1 is involved in the reorganization of F-actin. This also indicates that the function of Rac1 is altered during growth cone collapse.

Growth cone collapse induced by ephrin-A2 and semaphorin $3 \mathrm{~A}$ appears to involve Rac1-mediated endocytosis. Endocytosis of the plasma membrane was increased in both retina and DRG growth cones in response to ephrin-A2 treatment. Endocytosis was induced with a time course that correlated with the resumption of Rac1 activity after its transient decrease. Inhibition of Rac1 activity blocked induction of endocytosis in response to ephrin-A2 or semaphorin $3 \mathrm{~A}$, but it had no effect on constitutive endocytosis. This finding is consistent with a previous study suggesting that constitutive endocytosis is regulated differently than evoked endocytosis (Diefenbach et al., 1999; Ellis and Mellor, 2000). It was reported that Rac1 is targeted to sites of endocytosis during growth cone collapse (Fournier et al., 2000), which is also consistent with our findings. However, the role of endocytosis in growth cone collapse is not clear. Growth cone collapse induced by pharmacological depolymerization of F-actin did not result in increased endocytotic activity. Additionally, neurotrophins cause increased endocytosis at the growth cone, which is not associated with growth cone collapse but rather with growth cone formation and activity (V. Dontchev and P. C. Letourneau, unpublished data). Thus, Rac1-mediated endocytosis may be required for ephrin- or semaphorin-induced growth cone collapse, but endocytosis does not appear to be essential or sufficient to induce collapse.

Previous work established that ephrin signaling via Eph receptors is involved in development of the normal pattern of axonal projections in the primary visual system (Flanagan and Vanderhaeghen, 1998; O'Leary et al., 1999; Wilkinson, 2000; Yates et al., 2001). We reasoned that if Rac1 is a required effector of ephrin signaling in vivo, as indicated by the in vitro data, then reducing Rac1 expression should mimic the effect of reduced EphA3 expression on development of the retinal projection. We used an antisense oligonucleotide to reduce expression of Rac1 by retinal cells in vivo during the developmental period in which the retinal axons form connections. Retrograde axon labeling showed that 
normal topography failed to develop in the retinotectal projection after Rac1 antisense treatment. A similar result was obtained when the developing retina was treated with an EphA3 antisense oligonucleotide (Jurney, Selski, and McLoon, unpublished results). This shows that Rac1 is required for development of the normal pattern of axonal projections in the primary visual system. These findings are also consistent with Rac1 having an obligatory role in mediating ephrin signaling in vivo.

Negative guidance molecules are important for determining the wiring pattern of the nervous system. In tissue culture, these factors initiate collapse of growth cones. The findings reported here indicate that the negative guidance molecules ephrin-A2 and semaphorin $3 \mathrm{~A}$ initiate a change in function of Rac1 contributing to growth cone collapse. When axons are extending, Rac1 regulates polymerization of actin in growth cones and promotes the formation of a meshwork of F-actin in lamellipodia (Fig. 7A; Kuhn et al., 2000). After exposure to collapse-inducing factors, Rac1 is transiently inactivated (Fig. $7 B$ ). On resumption of activity, Rac1 mediates membrane endocytosis and F-actin reorganization (Fig. 7C). Thus, Rac1 has at least two independent functions in growth cones, and ephrin or semaphorin signaling leading to growth cone collapse requires coordination of several signal transduction pathways.

\section{REFERENCES}

Aizawa H, Wakatsuki S, Ishii A, Moriyama K, Sasaki Y, Ohashi K, Sekine-Aizawa Y, Sehara-Fujisawa A, Mizuno K, Goshima Y, Yahara I (2001) Phosphorylation of cofilin by LIM-kinase is necessary for semaphorin 3A-induced growth cone collapse. Nat Neurosci 4:367-373.

Allen MJ, Shan X, Murphey RK (2000) A role for Drosophila Drac1 in neurite outgrowth and synaptogenesis in the giant fiber system. Mol Cell Neurosci 6:754-765.

Baas PW, Luo L (2001) Signaling at the growth cone: the scientific progeny of Cajal meet in Madrid. Neuron 32:981-984.

Behar O, Golden JA, Mashimo H, Schoen FJ, Fishman MC (1996) Semaphorins act as attractive and repulsive guidance signals during the development of cortical projections. Nature 383:525-528.

Bernard V, Bohl BP, Bokoch GM (1999) Characterization of Rac and Cdc42 activation in chemoattractant-stimulated human neutrophils using a novel assay for active GTPases. J Biol Chem 274:13198-13204.

Cheng H-J, Nakamoto M, Bergemann AD, Flanagan JG (1995) Complementary gradients in expression and binding of ELF-1 and Mek4 in development of the topographic retinotectal projection map. Cell 82:371-381.

Diefenbach TJ, Guthrie PB, Stier H, Billups B, Kater SB (1999) Membrane recycling in the neuronal growth cone revealed by FM1-43 labeling. J Neurosci 19:9436-9444.

Dorseuil O, Vazquez A, Lang P, Bertoglio J, Gacon G, Leca G (1992) Inhibition of superoxide production in $\mathrm{B}$ lymphocytes by Rac antisense oligonucleotides. J Biol Chem 267:20540-20542.

Drescher U, Kremoser C, Handwerker C, Loschinger J, Noda M, Bonhoeffer F (1995) In vitro guidance of retinal ganglion cell axons by RAGS, a $25 \mathrm{kDa}$ tectal protein related to ligands for Eph receptor tyrosine kinases. Cell 82:359-370.

Edwards DC, Sanders L, Bokoch GM, Gill GN (1999) Activation of LIM-kinase by Pak1 couples $\mathrm{Rac} / \mathrm{Cdc} 42$ GTPase signaling to actin cytoskeletal dynamics. Nat Cell Biol 1:253-259.

Ellis S, Mellor H (2000) Regulation of endocytic traffic by rho family GTPases. Trends Cell Biol 10:85-88.

Ernst AF, Gallo G, Letourneau PC, McLoon SC (2000) Stabilization of growing retinal axons by the combined signaling of nitric oxide and brain-derived neurotrophic factor. J Neurosci 20:1458-1469.

Fan J, Raper JA (1995) Localized collapsing cues can steer growth cones without inducing their full collapse. Neuron 14:263-274.

Feldheim DA, Kim YI, Bergemann AD, Frisen J, Barbacid M, Flanagan JG (2000) Genetic analysis of ephrin-A2 and ephrin-A5 shows their requirement in multiple aspects of retinocollicular mapping. Neuron 25:563-574.

Flanagan JG, Vanderhaeghen P (1998) The ephrins and Eph receptors in neural development. Annu Rev Neurosci 21:309-345.
Fournier AE, Nakamura F, Kawamoto S, Goshima Y, Kalb RG, Strittmatter SM (2000) Semaphorin3A enhances endocytosis at sites of receptor-F-actin colocalization during growth cone collapse. J Cell Biol 149:411-422.

Frisen J, Yates PA, McLaughlin T, Friedman GC, O'Leary DD, Barbacid M (1998) Ephrin-A5 (AL-1/RAGS) is essential for proper retinal axon guidance and topographic mapping in the mammalian visual system. Neuron 20:235-243.

Hall A (1998) Rho GTPases and the actin cytoskeleton. Science 279:509-514.

Jin Z, Strittmatter SM (1997) Rac1 mediates collapsin-1-induced growth cone collapse. J Neurosci 17:6256-6263.

Korey CA, van Vactor D (2000) From the growth cone surface to the cytoskeleton: one journey, many paths. J Neurobiol 44:184-193.

Kuhn TB, Brown MD, Wilcox CL, Raper JA, Bamburg JR (1999) Myelin and collapsin-1 induce motor neuron growth cone collapse through different pathways: inhibition of collapse by opposing mutants of rac1. J Neurosci 19:1965-1975.

Kuhn TB, Meberg PJ, Brown MD, Bernstein BW, Minamide LS, Jensen JR, Okada K, Soda EA, Bamburg JR (2000) Regulating actin dynamics in neuronal growth cones by ADF/cofilin and Rho family GTPases. J Neurobiol 44:126-144.

Letourneau PC (1996) The cytoskeleton in nerve growth cone motility and axonal pathfinding. Perspect Dev Neurobiol 4:111-123.

Letourneau PC, Shattuck TA, Ressler AH (1987) "Pull" and "push" in neurite elongation: observations on the effects of different concentrations of cytochalasin B and taxol. Cell Motil Cytoskeleton 8:193-209.

Luo Y, Raible D, Raper JA (1993) Collapsin: a protein in brain that induces the collapse and paralysis of neuronal growth cones. Cell 75:217-227.

Maekawa M, Ishizaki T, Boku S, Watanabe N, Fujita A, Iwamatsu A, Obinata T, Ohashi K, Mizuno K, Narumiya S (1999) Signaling from Rho to the actin cytoskeleton through protein kinases ROCK and LIM-kinase. Science 285:895-898.

McLoon SC, Barnes RB (1989) Early differentiation of retinal ganglion cells: an axonal protein expressed by premigratory and migrating retinal ganglion cells. J Neurosci 9:1424-1432.

Monschau B, Kremoser C, Ohta K, Tanaka H, Kaneko T, Yamada T, Handwerker C, Hornberger MR, Loschinger J, Pasquale EB, Siever DA, Verderame MF, Muller BK, Bonhoeffer F, Drescher U (1997) Shared and distinct functions of RAGS and ELF-1 in guiding retinal axons. EMBO J 16:1258-1267.

Newsome TP, Schmidt S, Dietzl G, Keleman K, Asling B, Debant A, Dickson BJ (2000) Trio combines with Dock to regulate Pak activity during photoreceptor axon pathfinding in Drosophila. Cell 101:283-294.

O'Leary DDM, Yates PA, McLaughlin T (1999) Molecular development of sensory maps: representing sights and smells in the brain. Cell 96:255-269.

Ruchhoeft ML, Ohnuma S, McNeill L, Holt CE, Harris WA (1999) The neuronal architecture of Xenopus retinal ganglion cells is sculpted by rho-family GTPases in vivo. J Neurosci 19:8454-8463.

Steven R, Kubiseski TJ, Zheng H, Kulkarni S, Mancillas J, Rui Zmorales A, Hogue CW, Pawson T, Culotti J (1998) UNC-73 activates the Rac GTPase and is required for cell and growth cone migrations in $C$. elegans. Cell 92:785-795.

Taniguchi M, Yuasa S, Fujisawa H, Naruse I, Saga S, Mishina M, Yagi T (1997) Disruption of semaphorin III/D gene causes severe abnormality in peripheral nerve projection. Neuron 19:519-530.

Vastrik I, Eickholt BJ, Walsh FS, Ridley A, Doherty P (1999) Sema3Ainduced growth-cone collapse is mediated by Rac1 amino acids 17-32. Curr Biol 9:991-998.

Wahl S, Barth H, Ciossek T, Aktories K, Mueller BK (2000) Ephrin-A5 induces collapse of growth cones by activating rho and rho kinase. J Cell Biol 149:263-270.

Wilkinson DG (2000) Topographic mapping: organising by repulsion and competition? Curr Biol 10:R447-R451.

Wu HH, Selski DJ, El-Fakahany EE, McLoon SC (2001) The role of nitric oxide in development of topographic precision in the retinotectal projection of chick. J Neurosci 21:4318-4325.

Yamagata M, Jaye DL, Sanes JR (1994) Gene transfer to avian embryos with a recombinant adenovirus. Dev Biol 166:355-359.

Yang N, Higuchi O, Ohashi K, Nagata K, Wada A, Kangawa K, Nishida E, Mizuno K (1998) Cofilin phosphorylation by LIM-kinase 1 and its role in Rac-mediated actin reorganization. Nature 393:809-812.

Yates PA, Roskies AL, McLaughlin T, O'Leary DDM (2001) Topographic-specific axon branching controlled by Ephrin-As is the critical event in retinotectal map development. J Neurosci 21:85488563. 